\title{
The Application of Register Analysis into Translation Quality Assessment
}

\author{
Ningwei Yang \\ Xinlian College of Henan Normal University, Xinxiang, China
}

\begin{abstract}
Register analysis, an essential part of SFL, is composed of three variables, that is, field, mode and tenor. According to SFL, register forms the interface between the social system and the linguistic system; its elements realize social meanings and are realized in linguistic forms. In the process of translating, translators by and large confront problems not only at the linguistic level but also cultural level. As a powerful tool, register theory is practical and necessary to be introduced into translation studies. This paper tries to explore literary translation from the perspective of SFL and evaluate the version of Beiying by Zhang Peiji respectively from the field, mode and tenor. Based on findings, it is safe to say that register analysis to some degree makes a valuable contribution to translation quality assessment (TQA).
\end{abstract}

Index Terms—register analysis, translation quality assessment (TQA), Beiying

\section{Systemic Functional Linguistics (SFL)}

From different starting points, two main approaches - through form and through meaning - have formulated since Saussure initiated the linguistic studies. The most influential version of the approach through form is known as Transformational Generative (TG) approach proposed by Noam Chomsky. TG exclusively focuses on what we call "propositional meaning"- the "content" of the sentence, that is, "meaning" in the narrow sense. In TG a sentence is analyzed in isolation, without considering its context of co-text and context of situation and culture. The other approach through meaning is known as functional grammar which centers on the "choice" of meaning and wording, and it takes linguistics towards sociology. Simply speaking, the form-based approach finds the answer in the way our brains are structured whereas the meaning-based approach finds it in the way our social context is structured (Thompson,2008). SFL proposed by M.A.K.Halliday develops from Firth's system-structure theory in the 1930s. Halliday also inherits and promotes context theory put forward by Malinowski and Firth. On one hand, he probes into the influence contextual factors on the language system from the perspective of social semiotics. On the other hand, he proposes register theory and points out its three parameters, three metafunctions and the dialectic relationship between semantic system and its elements. Three important characteristic features of SFL can be summed up. Firstly, SFL centers on the sociological aspects of language; Secondly, the language is regarded as a form of doing rather than knowing. It distinguishes linguistic behaviour potential from actual linguistic behaviour. Thirdly, it gives a relatively high priority to the description of characteristics of particular languages and varieties of languages.

\section{The Hallidayan Model of Language ANd Discourse}

Discourse analysis made its debut in the early 1950s when Zellig Harris published his article entitled Discourse Analysis. Since the 1980s it has been on the right track and achieved innumerable results. The linguists such as Austin, Searle, Grice, Levinson, Leech, Hymes, Gumperz ,Van Dijk and so on have made a great contribution. In spite of different approaches they adopt, one common decision could be simplified as follows: language should be regarded as a dynamic social interactive phenomenon. Meaning is not conveyed by single or isolated sentences. We should take into consideration not only the people who use the language but also the world in which language is used. The most influential model of discourse analysis is Halliday's systemic functional model.

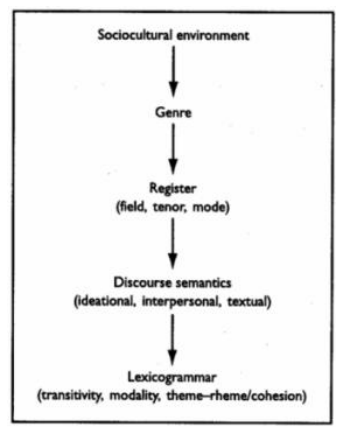

Figure1.Relation of Genre and Register to Language (Munday, 2001, p.90) 
The discourse analysis model proposed by Halliday is to delve into the language in use on the basis of SFL. And it mainly concerns itself with the relationship between language and context. Form the figure above, it can be seen that there is a strong interrelation between the surface-level realizations of the linguistic functions and the sociocultural framework. Genre is determined by sociocultural environment, at the same time, genre itself determines three elements or variables of register, that is, field, tenor and mode. Then those three variables are connected with three metafunctions of discourse semantics respectively, that is, ideational, interpersonal and textual. The field is associated with ideational meaning and the tenor interpersonal meaning as well as the mode textual meaning. And the latter three meanings are realized by the transitivity, modality, theme-rhemelcohesion respectively. The overall aspects of translation at different levels and the interrelation among them may be described and explained under this discourse analysis model. However, Halliday's grammar is so complicated that the scholars generally select one part of it or simplify it for their study.

\section{Register: A THEORY ON LANGUAGE VARIATION}

The purpose of utilizing language is communication. The successful communication on a large scale depends on different language varieties used in different situations. For example, the talk between intimate friends varies from the inauguration speech in public, and the lectures for students in classroom differ from the sermons preached by priests on the need of charity. Briefly speaking, text or discourse, written or spoken, is closely linked with the situation of context. In other words, languages vary according to their functions and they differ from each other in different situations. The name given to a variety of language distinguished according to use is register. The different register has its own characteristics of diction, structure, sentence-making and so on. That is to say, "register are defined in terms of differences in grammar, vocabulary, etc., between two samples of language activity such as a sports commentary and a church service" (Hatim\&Mason, 1990, p. 46). In other words, theories of register aim to propose relationships between language function (determined by situational or social factors) and language form.

Every discourse or text grows out of the given context and every discourse has its own register. Halliday(1976) states "the linguistic features which are typically associated with a configuration of situational features — with particular values of the field, mode and tenor-constitute a register.(p.22)" Each of three parameters has its own markers respectively on the phonological level, lexical level, grammatical level and textual level. It is beneficial for translator to analyze and decide the register of ST, hence establish the register equivalence in the TT. Only in this way may the ST turns out to be equivalent to the TT at utmost and reach the goal of functional equivalence on the text level.

\section{Three VAriables And the Establishment of Register EQuiValence}

In communication events people are prone to select different language varieties according to the different purposes they want to reach, the different partners they talk with and the different channels they employ. These three factors are manifested as three variables - field, tenor and mode - in the theory of register. In the discourse translation, a translator has to confront two assignments with the aim to accomplishing successful interlingual translation. Firstly, as a reader, it is necessary for the translator to make a close analysis of the field, tenor and mode from the different angles in the ST. And secondly, he needs to figure out the corresponding characteristics of three variables in the TT, especially those different from the ST. The three variables supplement each other and a good command of them is an essential step in translation. Only an overall consideration on them can guarantee the conformability of register between the ST and TT.

Field is also named as "domain" and "province". Some theorists hold the view that field of discourse refers to subject matter. For example, Bell (2001) says "in a very much broader sense, domain refers to ... family, friendship, education and so forth" (p.191), which sounds very much like subject matter. However, someone else argues that the definition is not accurate enough and those two notions are not identical to some degree. John Pearce suggests field of discourse "embraces not only the subject-matter in hand but the whole activity of the speaker or participant in a setting" (Doughty et al., 1972, p.185). It is apparent that the discussion above lays its emphasis on the activity part, that is, what is going on, rather than what is talking about.

Generally speaking, the mode of discourse refers to the medium or channel through which the communication takes place. According to Gregory (1978), the relation of a user to his medium may be seen as the simple one of he is using - speech or writing. In translation, it is not allowed for translator to change the mode of ST. if the original text is colloquial style, the target text is better to be brought into correspondence with it.

The tenor of discourse is a conception accounting for the social relation between author lspeaker and readerllistener and the relation (formal relation, imitate relation and casual relation) among the characters in the discourse. The tenor of discourse can be discussed at four overlapped levels: formality, politeness, impersonality and acceptability (Bell, 2001). What actually determines this degree of distance and consequent formality may be social status or the authority that comes with knowledge or something as simple as available space (Fawcett, 199712007). The tenor can be decided through the different vocabulary and titles employed in the text. For example, an imitate relation can be represented by simple sentences, the usage of dialect and slang language. Meanwhile, solemn and formal relation can be expressed through complicated syntactic structures, proper nouns and archaic words. As usual, a translator has no right to change the tenor of ST. An imitate conversation can not be translated into a serious sermon. A public speech can not be translated into the colloquialism either. It is necessary for translator to understand what the tenor of ST is and represent 
the corresponding relation in the TT. In the process of translating, translators sometimes have to make some changes about tenor because of the different cultural background, hence create a new relationship among participants in the target text. Namy relates how interpreting between American and French trade union officials involves a constant shift of tenor. Whereas the French make deliberate use of an educated formal tenor, their American counterparts conventionally do the opposite, displaying their working-class allegiance with liberal use of colloquialisms, etc. (Hatim \& Mason, 1990)

A comprehensive understanding of resister theory and a good command of its three parameters are inevitably helpful for translator to select some appropriate approaches and strategies for better translation. Only the equivalence of filed, mode and tenor can assure the equivalence between ST and TT which can lead the unity of language forms and its communication situation, communication purposes and the status of involved participants.

\section{Quality Assessment of the English Version of Beiying: A Case Study}

\section{A. TQA Based on Field Equivalence}

The original text of Beiying is a short prose and a majority of sentences employed are not long. It once appeared in the textbook for middle school students, so the vocabulary used in it is not complex. In this part, Wordsmith, a kind of software, is employed to analyze the version by Zhang Peiji (2007) in an attempt to judge whether the TT is equivalent to the ST or not in terms of form.

TABLE I.

THE CORPUS-BASED ANALYSIS OF ZHANG'S VERSION

\begin{tabular}{|c|c|c|c|c|}
\hline \multicolumn{7}{|c|}{ THE CORPUS-BASED ANALYSIS OF ZHANG'S VERSION } \\
\hline tokens & types & TTR & Standardised TTR & Mean word length \\
\hline 1139 & 442 & 39 & 39.90 & 4 \\
\hline sentences & 1-letter word & 2-letter word & 3-letter word & 4-letter word \\
\hline 64 & 73 & 213 & 255 & 178 \\
\hline
\end{tabular}

From the table above, the following four points could be concluded: (1) The number of token 1139, the number of type 442 and the number of sentence 64 suggest that this text is not long; (2) Type-token ratios tells us something about the variety of vocabulary used in a corpus, so TTR 39 and the Standardised TTR 39.90 indicate that the variation of vocabulary is not evident; (3) The sum of 1-letter word, 2-letter1word, 3-letter word and 4-letter word is 719 which occupies 63 percent of the whole text. It proves the vocabulary adopted by the translator is not hard or beyond the average reader's capacity; (4) The word "was" with a high frequency shows the main tense is past tense, which is in line with that of original text. After the overall analysis of the whole text, the following part turns to the specific examples.

Example 1

ST: 到徐州见着父亲, 看见满院狼藉的东西, 又想起祖母，不禁籁籁地流下眼泪。

TT: When I met father in Xuzhou, the sight of the disorderly mess in his courtyard and the thought of grandma started tears trickling down my cheeks.

In the original text, the inner logical relation among clauses can be shown as 父亲 (father) +满院狼藉 (disorderly mess ) +逝去的祖母 (the thought of grandma) $\longrightarrow$ 流泪 (tears). However, the logical relation in the target text is changed into 满院狼藉 (disorderly mess) + 想起祖母 (the thought of grandma) $\longrightarrow$ 流泪 (tears). Evidently, Zhang's version can not fully reproduce the original logical relation in the target text. The author tries to find out a solution which is shown as the following:

\section{Revisited version:}

When I arrived in Xuzhou, the meeting with father, the sight of the disorderly mess in our courtyard and the thought of grandma started tears tricking down my cheeks.

Compared with Zhang's version, the subject is made up of three paralleled phrases (the meeting with father, the sight of the disorderly mess in our courtyard and the thought of grandma) which fully reproduce the logical relation in the ST, hence represents the emotion in the original text.

\section{Example 2}

$\mathrm{ST}$ : 他走了几步, 回过头看见我, 说, “进去吧, 里边没人。”等他的背影混入来来往往的人里, 再找不着了, 我便进来坐下, 我的眼泪又来了。

TT: After a few steps, he looked back at me and said, "Go back to your seat. Don't leave your things alone." I, however, did not go back to my seat until his figure was lost among crowds of people hurrying to and fro and no longer visible. My eyes were again wet with tears.

When deal with “进去吧，里边没人”, there are two choices, that is, word-for-word translation and sense-for-sense translation, which can produce two different versions. Zhang chooses the latter and translates it as "Go back to your seat. Don't leave your things alone.” which is not equivalent to “进去吧, 里边没人” in terms of form. However it guarantees the function equivalence. If we translate it as "there is no one in the compartment" which just represents the external meaning, the target readers would have misunderstood the meaning expressed in the original text.

\section{Example 3}

$\mathrm{ST}$ : 近几年来，父亲和我都是东奔西走。 
TT: In recent years, both father and I have been living an unsettled life, and the circumstances of our family going from bad to worse.

In English it is hard for us to find a ready-made phrase which can fully express the meaning of the Chinese idiom Dong ben xi zou (东奔西走). Yang Xianyi employs “moving from place to place" to render it. However, it seems not an appropriate answer because "move" means "to go to live or work in a different place, or cause someone to do this" and it can not represent the deeply meaning of Dong ben xi zou, that is, having to go in all direction for living. Meanwhile, "living an unsettled life" is not a good solution either because it fails to visualize the image shown by Dong ben xi zou, that is, rushing here and there. So in author's opinion, the Zhang's version can be polished as the following:

Revisited version: In recent years, both my father and I have been rushed here and there to stay alive, while the circumstances of our family gone from bad to worse.

"rush here and there" to some extent reproduces the semantic meaning of Dong ben xi zou and the addition "to stay alive" expresses the helplessness of living.

\section{B. TQA Based on Tenor Equivalence}

\section{Example 4}

$\mathrm{ST}$ : 父亲是一个胖子, 走过去自然要费事些。

TT : That would be a strenuous job for father, who was fat.

“胖子” here is employed to depict the father's stout figure with the purpose of emphasizing the difficulty he confronts when goes across the railway and stressing the deeply love towards his son. Mr. Zhang renders “胖” as “fat” which is a derogatory word. "Fat" is not apt to describe a father, especially in this context. To avoid crudity, maybe it is a wise idea to translate "胖" as "stout" which is a neutral term.

\section{Example 5}

ST: 又嘱托茶房好好照应我。我心里暗笑他的迂; 他们只认得钱，托他们简直是白托！而且我这样大年纪的 人, 难道还不能料理自己么? 唉, 我现在想想, 那时真是太聪明了!

TT: He also asked the train attendants to take good care of me. I sniggered at father for being so impractical, for it was utterly useless to entrust me to those attendants, who cared for nothing but money. Besides, it was certainly no problem for a person of my age to look after himself. Oh, when I come to think of it, I can see how smarty I was in those days!

“聪明” in Chinese is for the most part a commendatory word. However, through a closely analysis, it is evident to see in the example above “聪明” is not a commendatory word, but a derogatory one. The author is not inclined to praise himself, but regret for his disrespect for his father. Here, the irony, a kind of figure speech, is employed to satirize the author himself. So “聪明” could not be translated as directly "smart", "bright”, or “clever". Based on the closely observation, Mr.Zhang chooses “smart aleck" and “smarty” to render “聪明”. These two words well reproduce the affection expressed in the source text.

\section{Example 6}

$\mathrm{ST}$ : 于是扑扑衣上的泥土, 心里很轻松似的, 过一会说, “我走了; 到那边来信! ”

TT: he laid all the tangerines on my overcoat, and patting the dirt off his clothes, he looked somewhat relieved and said after a while, "I must be going now. Don't forget to write me from Beijing".

If “我走了” is translated as "I am going now" directly, the father's emotion of missing and concerning would be weakened to some degree, although the TT is equivalent to the ST in terms of form. If we put a modal verb into this sentence, the emotion of missing from father to his son could be fully manifested because "must go" means "have to go" which suggests that the father is unwillingly to leave. The form is different, but the function is of equivalence.

\section{Example 7}

ST: 我说道, “爸爸, 你走吧”。

TT: I said, "Dad, you might leave now."

This is a conversation between father and his son. “爸爸, 你走吧” is an imperative sentence, but the tone is not ordering or requesting, but suggesting. It is not hard for people in Chinese-speaking regions to figure out it, and the readers naturally understand its connotative meaning. If we translate it as "Dad, you leave now." which is an evident imperative sentence, the target readers could not understand why the son is so impolite to his father because of the change from suggestion to order. Furthermore, that shift not only spoils the emotion of missing but also ruins the traditional relationship between father and son in the modern China. When translating the short clause “你走吧”, Mr. Zhang just adds a modal verb "might". With its help, the author's respect and attachment to his father and the superior status of his father are fully manifested. Zhang's version turns out acceptable for the target readers because it not only successfully delivers the affection but also softens the tone of toughness existing in the source text.

\section{TQA Based on Mode Equivalence}

\section{Example 8}

$\mathrm{ST}$ : 父亲因为事忙, 本已说定不送我, 叫旅馆里一个熟识的茶房陪同我去。

TT: Father said he was too busy to go and see me off at the railway station, but would ask a hotel waiter that he 
knew to accompany me there instead.

In most cases “父亲” is employed by author to address his father. In order to make the style or mode of TT conform to that of ST. Mr. Zhang doesn't change it and he renders “父亲” as a formal word "father".

\section{Example 9}

$\mathrm{ST}$ : 我说道, “爸爸, 你走吧。”

TT: I said, “Dad, you might leave now."

This is a private conversation and the address form “爸爸” expresses the author's deeply attachment to his father although it is a simple word. In order to conduct the equivalence of mode, translator chooses a colloquial word "Dad" in place of "father".

\section{Example 10}

ST: 他只说, “不要紧, 他们去不好! ”

TT: but he only said, "Never mind! It won't do to trust guys like those hotel boys!"

Here Mr. Zhang makes a few minor adjustments to the mode of source text. “他们” is decoded as "guys like those hotel boys" instead of "them", through which the free and easy conversation between the son and father is well represented before readers.

\section{CONCLUSION}

Linguistic approaches view translation as a kind of social activity and aim to explore the functions and influences of translation in the target language. However, the linguistic approaches can not solve all problems of translation and they should be seen as just the one, rather than the only one, of accounting for the translation process (Fawcett, 199812004). We should understand their contribution in a reasonable way. Someone holds that we can not carry on literature criticism through linguistic theories because the literature is just for appreciation, and not apt to be analyzed, let alone from the linguistic perspective. They compare linguistic theory to "a knife of taking part a beautiful woman". The author does not approve of that. From the discussion above, we can see that the present studies of prose translation are still in the groping stage. However, an increasing number of linguistic theories have been applied into translation studies, especially literary translation. Among them, context theory and register analysis, two core theories of SFL, have broadened the previous scope of translation studies and served as powerful tools for the analysis of prose translation. Translation scholars must recognize that no approach, however sophisticated, can provide a perfect answer to avoiding subjectivity to the core in the process of TQA because of the assessors' various educational levels and different social and cultural backgrounds. Wolfram Wilss (2001) points out the insights of translation criticism rarely, even never reach the level as accurate as natural science. The application scope of translation criticism is restricted because of the fact that translation is an activity of language use. Considering the complexity of subject matter and the variety of approaches, the practice of making translation criticism absolutely scientific seems not unwise and nonsense.

\section{REFERENCES}

[1] Bell, R.T. (199112001). Translation and Translating: Theory and Practice. Beijing: Foreign Language Teaching and Research Press.

[2] Doughty et al. (1972). Language in use. London: Edward Amold.

[3] Fawcett, P. (199712007). Translation and Language: Linguistics Theories Explained. Beijing: Foreign Language Teaching and Research Press.

[4] Fawcett, P. (199812004). Linguistic approaches. In M. Baker (ed.) Routledge Encyclopedia of Translation Studies. Shanghai: Shanghai Foreign Language Education Press.

[5] Gregory, M. \& Susanne, C.(1978). Language and Situation: Language Varieties and Their Social Contexts. London: Routledge \& Kegan Paul Led.

[6] Halliday, M.A.K. \& Hasan, R. (1976). Cohesion in English. London: Longman.

[7] Hatim, B.\& I, Mason. (1990). Discourse and Translator. Longman Group UK Limited.

[8] Munday, J. (2001). Introducing Translation Studies: Theories and Application. London and New York: Routledge.

[9] Peiji,Zhang. (2007). Selected Modern Chinese Essays1.Shanghai: Shanghai Foreign Language Education Press.

[10] Thompson, G. (2008). Introducing Functional Grammar. Beijing: Foreign Language Teaching and Research Press.

[11] Wilss,W. (1982 2001). The Science of Translation: Problems and Methods. Shanghai: Shanghai Foreign Language Education Press.

Ningwei Yang was born in Puyang, China in 1988. He received his master degree in translation studies from Henan Normal University, China in 2012.

He is currently a lecturer in Xinlian College, Henan Normal University, China. His research interests include translation criticism and translation teaching. 